\title{
Simple and Accurate Representation of Bangla Numerals by 10-Segment Display Compared to 8- Segment Display
}

\author{
Tushar Kanti Roy
}

\begin{abstract}
Department of Electronics and Telecommunication Engineering, Rajshahi University of Engineering \& Technology, Rajshahi-6204, Bangladesh

*Corresponding Author: roy_kanti@yahoo.com
\end{abstract}

Copyright (C) 2014 Horizon Research Publishing All rights reserved.

\begin{abstract}
In the field of electronic devices, Digital logic system plays an important role. The rapid development of digital technology makes faster and easier life of a human being. Working in a unique field also gives a lot of pleasure. In this paper a new approach is chosen to start a journey with digital electronics. In the Electronic World Bangla language is neglected. The Bangla digital display is designed for the people of Bangladesh. On the other hand, Bangla numerals have more curved corners in comparison to English numerals. To represent English numerals, 7-segment display is so popular because of its simplicity and accuracy. Unlike English numerals, designing of simple and accurate segmented representation of Bangla numerals is still a research area of Bangla processing. Bangle numerals have some limitations of using more segments in displaying Bangla numerals. So, in this paper a new model of 10 -segment display is proposed for Bangla numerals to overcome these limitations.
\end{abstract}

Keywords Two Fabricated Bent Segments, Binary Coded Decimal (BCD), Combinational Vector

\section{Introduction}

Electrical and Electronics equipments play an indispensable role in everyday life. The most preferable language for those equipments is English but most of the people of Bangladesh are illiterate. Hence, for them learning English is quite impossible. A unique finite segmented display is [1-4] required to display Bangla numerals. For English numerals, 7- segment display is already accepted and used for a long time to display English numerals. It is a matter of great hope that the researchers of Bangla processing proposed some methods to represent Bangla numerals in the last few years. As a result different display architectures using a finite number of segments have been proposed for displaying Bangla numerals. To find the optimum number of segments we must have done more researches to reduce displaying cost, save memory space and produce qualitative outlook. The proposed model used only 10 -segment display to reduce display cost and save memory space of dot matrix display, also maintain the overall outlooks. To represent Bangla display only two fabricated bent segments have been used. The proposed segmented display also avoids segment overlapping, used an optimal number of segments, avoid an unwanted number of gaps between two consecutive characters, produce uniform numerals and improve the accuracy of representation. The rest of this paper is organized as follows. Section II briefly introduces the model which is used in Section IV to represent the Bangla numerals. The comparison between proposed model and existing model is presented in section III. Finally, the paper is concluded in Section V.

\section{The Proposed 10-Segment Display Model}

The proposed 10-segment display model is shown in the Fig.1. The segments are non-overlapping and labeled with specific alphabet. In this paper LEDs are used to illuminate the segments. For a definite digit, particular segments will be $\mathrm{ON}$ (HIGH) and the others will be OFF (LOW), so it is necessary to mark the segments which can be displayed all the Bangla numerals accurately and uniformly.

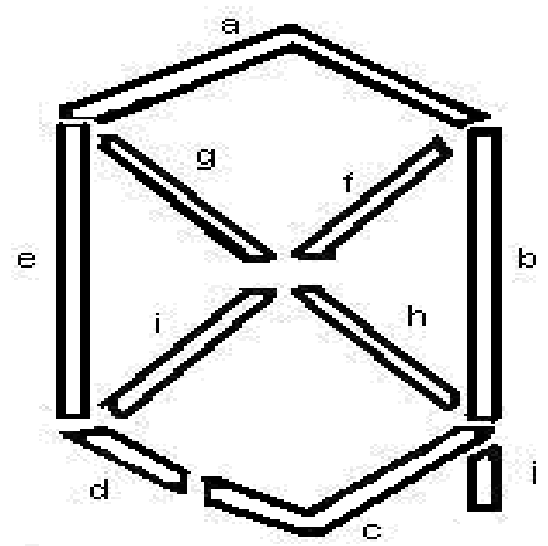

Figure 1. The Proposed 10-Segment display Model 


\section{Comparison between Proposed Display and Existing Display}

The comparison between existing 8-segment [5] display and proposed 10-segment display for some Bangla numerals are shown in following Fig.2 and Fig.3.

Bangle numeral seven in proposed 10-segment display

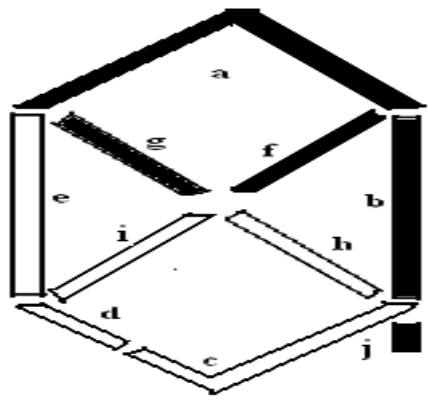

Bangle numeral seven in existing 8-segment display

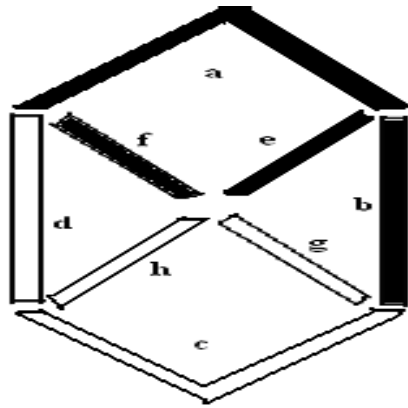

Figure 2. Comparison between Proposed display and Existing display

In the above displays there are changes between existing 8-segment display and 10-segment display for displaying seven. In existing 8-segment display the Bangla numeral seven is not similar with Sutonny numeral. But in 10segment display the Bangla numeral seven is approximately similar with Sutonny numeral.

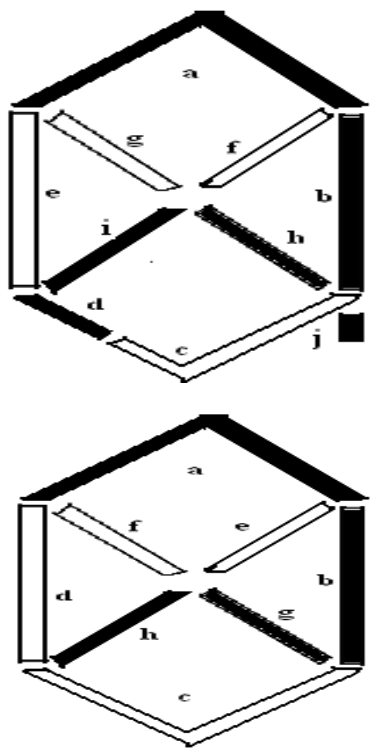

Figure 3. Comparison between proposed display and existing display
In the above displays there are changes between existing 8-segment display and 10-segment display for displaying nine. In existing 8-segment display the Bangla numeral nine is not similar with Sutonny numeral. But in 10- segment display the Bangla numeral nine is approximately similar with Sutonny numeral.

\subsection{Functional Representation of Bangla Numeral for Both Models}

As there are ten Bangla numerals. So, the segment decoding logic requires four [6-8] Binary Coded Decimal (BCD) input and 10-segment outputs. The truth table is depicted in Table 1 and Table 2.

Table 1. Truth table for 10 -segment Bangla numerals

\begin{tabular}{|c|c|c|c|c|c|c|c|c|c|c|c|c|c|c|}
\hline \multirow{2}{*}{ Digit } & \multicolumn{10}{|c|}{ BCD Input } & \multicolumn{10}{|c|}{ Segments } \\
\cline { 2 - 16 } & w & $\mathrm{x}$ & $\mathrm{y}$ & $\mathrm{z}$ & $\mathrm{a}$ & $\mathrm{b}$ & $\mathrm{c}$ & $\mathrm{d}$ & $\mathrm{e}$ & $\mathrm{f}$ & $\mathrm{g}$ & $\mathrm{h}$ & $\mathrm{i}$ & $\mathrm{j}$ \\
\hline 0 & 0 & 0 & 0 & 0 & 1 & 1 & 1 & 1 & 1 & 0 & 0 & 0 & 0 & 0 \\
\hline 1 & 0 & 0 & 0 & 1 & 1 & 1 & 1 & 1 & 0 & 0 & 0 & 1 & 1 & 0 \\
\hline 2 & 0 & 0 & 1 & 0 & 1 & 0 & 1 & 1 & 0 & 0 & 1 & 1 & 0 & 0 \\
\hline 3 & 0 & 0 & 1 & 1 & 1 & 1 & 1 & 1 & 0 & 1 & 0 & 0 & 0 & 0 \\
\hline 4 & 0 & 1 & 0 & 0 & 1 & 0 & 1 & 1 & 0 & 1 & 1 & 1 & 1 & 0 \\
\hline 5 & 0 & 1 & 0 & 1 & 1 & 0 & 1 & 1 & 1 & 0 & 1 & 0 & 1 & 0 \\
\hline 6 & 0 & 1 & 1 & 0 & 0 & 0 & 1 & 1 & 1 & 0 & 1 & 0 & 1 & 0 \\
\hline 7 & 0 & 1 & 1 & 1 & 1 & 1 & 0 & 0 & 0 & 1 & 1 & 0 & 0 & 1 \\
\hline 8 & 1 & 0 & 0 & 0 & 0 & 0 & 1 & 1 & 1 & 0 & 1 & 1 & 1 & 0 \\
\hline 9 & 1 & 0 & 0 & 1 & 1 & 1 & 0 & 1 & 0 & 0 & 0 & 1 & 1 & 0 \\
\hline
\end{tabular}

Table 2. Truth table for 8-segment Bangla numerals

\begin{tabular}{|c|c|c|c|c|c|c|c|c|c|c|c|c|}
\hline \multirow{2}{*}{ Digit } & \multicolumn{9}{|c|}{ BCD Input } & \multicolumn{7}{|c|}{ Segments } \\
\cline { 2 - 14 } & $\mathrm{w}$ & $\mathrm{x}$ & $\mathrm{y}$ & $\mathrm{z}$ & $\mathrm{a}$ & $\mathrm{b}$ & $\mathrm{c}$ & $\mathrm{d}$ & $\mathrm{e}$ & $\mathrm{f}$ & $\mathrm{g}$ & $\mathrm{h}$ \\
\hline 0 & 0 & 0 & 0 & 0 & 1 & 1 & 1 & 1 & 0 & 0 & 0 & 0 \\
\hline 1 & 0 & 0 & 0 & 1 & 1 & 1 & 1 & 0 & 0 & 0 & 1 & 1 \\
\hline 2 & 0 & 0 & 1 & 0 & 1 & 0 & 1 & 0 & 0 & 1 & 1 & 0 \\
\hline 3 & 0 & 0 & 1 & 1 & 1 & 1 & 1 & 0 & 1 & 0 & 0 & 0 \\
\hline 4 & 0 & 1 & 0 & 0 & 1 & 0 & 1 & 0 & 1 & 1 & 1 & 1 \\
\hline 5 & 0 & 1 & 0 & 1 & 1 & 0 & 1 & 1 & 0 & 1 & 0 & 1 \\
\hline 6 & 0 & 1 & 1 & 0 & 0 & 0 & 1 & 1 & 0 & 1 & 0 & 1 \\
\hline 7 & 0 & 1 & 1 & 1 & 1 & 1 & 0 & 0 & 1 & 1 & 0 & 0 \\
\hline 8 & 1 & 0 & 0 & 0 & 0 & 0 & 1 & 1 & 0 & 1 & 0 & 1 \\
\hline 9 & 1 & 0 & 0 & 1 & 1 & 1 & 0 & 0 & 0 & 0 & 1 & 1 \\
\hline
\end{tabular}

In the above Table 1and 2, 1=High (active segment) and $0=$ Low (inactive segment).

\subsection{Combinational Vector for Each Numeral in Both Model}

The Combinational [5-8] vector for Bangla numerals using $10 \& 8$-segments are shown below in Table $3 \& 4$. 
Table 3. Combinational vector for 10-segment Bangla numerals

\begin{tabular}{|c|c|c|}
\hline Digit & $\begin{array}{c}\text { Bangle } \\
\text { numerals }\end{array}$ & $\begin{array}{c}\text { Combinational 10-segment vector for Bangla } \\
\text { numerals }\end{array}$ \\
\hline 0 & 0 & $\{a, b, c, d, e\}$ \\
\hline 1 & 1 & $\{a, b, c, d, h, i\}$ \\
\hline 2 & 2 & $\{a, c, d, g, h\}$ \\
\hline 3 & 3 & $\{a, c, d, f, g, d, f\}, i\}$ \\
\hline 4 & 4 & $\{a, c, d, e, f, g, i\}$ \\
\hline 5 & 5 & $\{c, d, e, g, i\}$ \\
\hline 6 & 6 & $\{a, b, f, g, j\}$ \\
\hline 7 & 7 & $\{a, b, e, g, h, i\}$ \\
\hline 8 & 8 & \{ \\
\hline 9 & 9 &
\end{tabular}

Table 4. Combinational vector for 8-segment Bangla numerals.

\begin{tabular}{|c|c|c|}
\hline Digit & $\begin{array}{c}\text { Bangle } \\
\text { numerals }\end{array}$ & $\begin{array}{c}\text { Combinational vector for 8-segment Bangla } \\
\text { numerals }\end{array}$ \\
\hline 0 & 0 & $\{a, b, c, d\}$ \\
\hline 1 & 1 & $\{a, b, c, g, h\}$ \\
\hline 2 & 2 & $\{a, c, f, g\}$ \\
\hline 3 & 3 & $\{a, c, e, f, g, e\}$ \\
\hline 4 & 4 & $\{a, c, d, f, h\}$ \\
\hline 5 & 5 & $\{c, d, f, h\}$ \\
\hline 6 & 6 & $\{a, b, e, f\}$ \\
\hline 7 & 7 & $\{a, d, f, h\}$ \\
\hline 8 & 8 & $\{a, g, h\}$ \\
\hline 9 & 9 &
\end{tabular}

\subsection{Sum of Product Function for Each Segment in Both Model}

The sum of product function of each segment is shown in Table 5 and Table 6, respectively.

Table 5. Sum of product function of 10-segments.

\begin{tabular}{|c|c|}
\hline Segment & Sum of product function of 10-segments \\
\hline a & $\sum(0,1,2,3,4,5,7,9)$ \\
\hline b & $\sum(0,1,3,7,9)$ \\
\hline c & $\sum(0,1,2,3,4,5,6,8)$ \\
\hline d & $\sum(0,1,2,3,4,5,6,8,9)$ \\
\hline e & $\sum(0,5,6,8)$ \\
\hline f & $\sum(3,4,7)$ \\
\hline g & $\sum(2,4,5,6,7,8)$ \\
\hline h & $\sum(1,2,4,8,9)$ \\
\hline i & $\sum(1,4,5,6,8,9)$ \\
\hline j & $\sum(7)$ \\
\hline
\end{tabular}

Table 6. Sum of product function for 8-segments.

\begin{tabular}{|c|c|}
\hline Segment & Sum of product function of 8-segments \\
\hline $\mathrm{a}$ & $\sum(0,1,2,3,4,5,7,9)$ \\
\hline $\mathrm{b}$ & $\sum(0,1,3,7,9)$ \\
\hline $\mathrm{c}$ & $\sum(0,1,2,3,4,5,6,8)$ \\
\hline $\mathrm{d}$ & $\sum(0,5,6,8)$ \\
\hline $\mathrm{e}$ & $\sum(3,4,7)$ \\
\hline $\mathrm{f}$ & $\sum(2,4,5,6,7,8)$ \\
\hline $\mathrm{g}$ & $\sum(1,2,4,9)$ \\
\hline $\mathrm{h}$ & $\sum(1,4,5,6,8,9)$ \\
\hline
\end{tabular}

\section{Implementation of Our Proposed Model}

Our proposed model is implemented by the following circuit diagram shown in Fig.4. In the below Fig.4, the output of the 555 Timer is applied to the decimal decade counter 4017. The LED display device will show the Bangla digit from zero to nine with respect to the decade counter 4017 inputs with the help of the 555 Timer. For example, for segment ' $\mathrm{e}$ ' will be on for displaying $0,5,6$ and 8 when the output Qo, Q5, Q6, Q8 of the 4017 active and corresponding transistors are biased to complete the circuit connection. On the other way, the segment ' $a$ ' which is on for displaying 0,1 , $3,4,5,7,9$ and at this time the circuit connection already exist and segment will be remain on, So, we need to off that particular segment. For this purpose, Q6, Q8 output of the 4017 and corresponding transistors are biased so that the corresponding segment is short circuited and it will remain off.

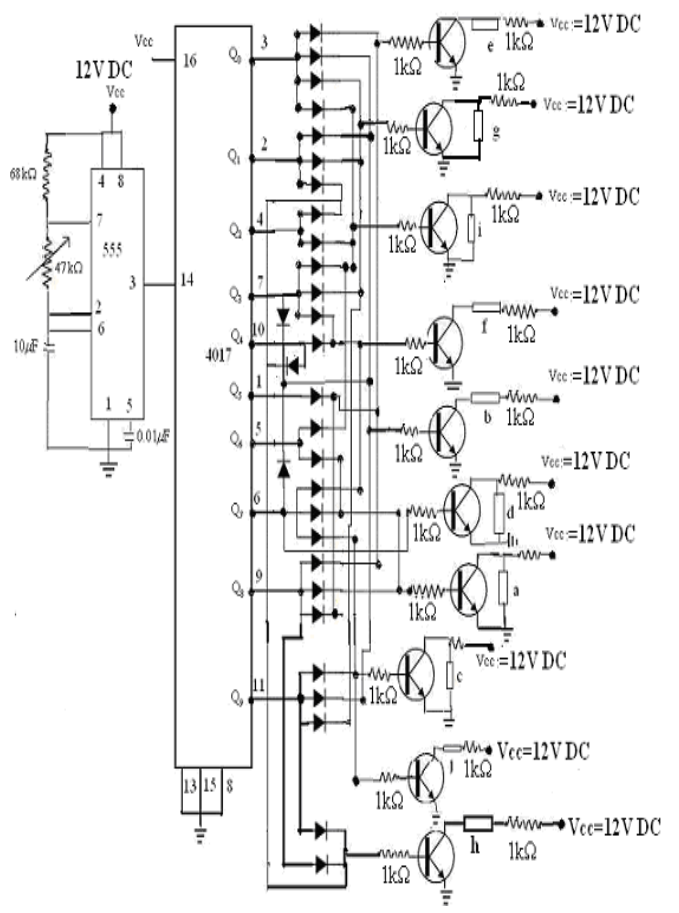

Figure 4. Circuit Diagram of 10-Segment Display 


\section{Conclusion and Discussion}

Unlike English numerals, the appearance of Bangla numerals is extremely dependent on the perfection of their curved corners. To design the segment, we used simple two angular to bend segments. In this paper the proposed 10 -segment display, displaying all the Bangla numerals uniformly and accurately. The implementation of Bangla numerals 7 and 9 was a challenging issue for 8 -segment display. In the existing 8-segment display there is a problem for displaying the Bangla numerals seven and nine uniformly and accurately. But the proposed 10-segment display overcomes these problems. In the proposed 10-segment display the Bangla numerals seven and nine are similar of the Sutonny seven and nine. So it is expected that this segment display may be used as an ideal circuit for displaying Bangla numerals.

\section{REFERENCES}

[1] Md. Abul Kalam Azad, Rezwana Sharmeen, Shabbir Ahmed and S.M. Kamruzzaman, 2005, “ A unique 10-segment display for Bangla Numerals" in proceedings of $8^{\text {th }}$ International Conference on Computer and Information Technology (ICCIT), Dhaka Bangladesh.
[2] Fazle Rabbi, Mohammad Kobir Hossain and Monzur Ahmed, 2003, "An 8-segments for both English and Bangla Digits " in proceedings of $6^{\text {th }}$ International Conference on Computer and Information Technology (ICCIT), Dhaka Bangladesh, pp. 299-302.

[3] Sk. Alamgir Hossain, Md. Iqbal Aziz Khan, 2004, "Displaying 14-segments for the English alphabet" in proceedings of $7^{\text {th }}$ International Conference on Computer and Information Technology (ICCIT), Dhaka Bangladesh, pp. 821-826.

[4] N. Mhamud and M. Rahman Khan, 2003, " Designing 9-segment display for Bangla Digits", in proceedings of $3^{\text {rd }}$ International Conference on Electrical and Computer Engineering (ICECE 2003), Dhaka Bangladesh.

[5] Shanawaz Islam, Md. Golam Rabiul Alam, Md. Nizam Uddin, 2006, "An 8-segment display for simple and accurate representation of Bangla Numerals" in proceedings of $4^{\text {th }}$ International Conference on Electrical and Computer Engineering (ICECE 2006), Dhaka Bangladesh.

[6] M. Morris Mano, "Digital logic and computer design"pp. 121-147

[7] Ronald J. Tocci and Neal S. Widmer, "Digital system Principles and Application." New Jersey: Prentice-Hall International .Inc, 2000

[8] William H.Gothmann, 1986, “P.E, 'Digital Electronics an Introduction to Theory and Practice" New Delhi: Prentice-Hall of India Private Limited. 